\author{
Olga Blanco ${ }^{1}$ and Javier Fernandez- \\ Rio $^{2 *}$ \\ ${ }^{1}$ Athletic Trainer, Alternative Therapies Practitioner, Spain \\ ${ }^{2}$ University of Oviedo, Spain \\ Dates: Received: 02 March, 2015; Accepted: 17 \\ March, 2015; Published: 19 March, 2015 \\ *Corresponding author: Dr. Javier Fernandez- \\ Rio, University of Oviedo, Spain, E-mail: javier. \\ rio@uniovi.es \\ www.peertechz.com \\ ISSN: 2455-5487
}

Keywords: Sport; Women's basketball; Injuries; Recovery; Treatment; Prevention

\section{Research Article \\ Lesional Incidence in a Women's Professional Basketball Team during a Complete Season}

\section{Introduction}

The importance of women's sport, despite its low media impact, it's a fact. In countries such as Spain, a large number of sporting successes in recent years have come from the hand of female athletes or women's teams in different disciplines and categories.

In the case of basketball, the numbers speak for themselves. In Spain, it is the female sport with the larger number of licenses [1], but in spite of this, there is little specific bibliography on women's basketball injuries.

We must take into account the complexity that represents the cataloging of an injury, as there are often different factors influencing them. In basketball, despite not being considered a contact sport, there is constant contact between players, of the opposing team and between partners. In addition, there are a wide variety of different actions involved in the sport: jumps, sprints, displacements, constant repetition of movements, etc, [2]. All this reasons make the classification of the lesions difficult.

Based on the aforementioned and taking advantage of our daily work with a division-II professional team, we decided to record all data during a complete season in order to be able to assess which were the main injuries that the players met on a daily basis. We were interested on the time of the season in which the injuries occurred, the incidence they had in the athletes' training and competition, and how to correct them using a multidisciplinary team: coach, athletic trainer and conditioning coach.

\section{Methods}

\section{Participants}

The experimental design used in this research project can be considered single-case, since the study was carried out with the total staff of a division-II women basketball team during the season
2013/2014: 11 players. They were all professional players which trained four days a week and competed every Saturday from October to May. The inclusion/exclusion criteria were: (1) participate in over $90 \%$ of the team practices, and (2) miss less that $10 \%$ of the official games.

\section{Material}

For data collection an excell table (Microsoft) was developed using the Questionnaire for Injury Incidence [3] as a benchmark. This assessment instrument was developed and validated by the Spanish Basketball Federation to be used by all the clubs competing in the national league. It is divided in two different parts:

In the first one, data from each player regarding date of the injury, week of the season in which it occurred, type, cause and location of the lesion, estimated time of recovery, treatment performed, number of practices and matches lost by the player, and total number of sessions needed for full recovery.

In the second part, data regarding the type of injury (articular, muscle, tendon, bone, and others...), as well as body part affected (upper limbs, lower limbs, spine, trunk or head) was recorded.

The execution of the research project involved two steps: first, permission from the Ethics Committee of the researchers' University and the players' club was obtained, and second, a written informed consent was signed by all the participants.

\section{Results}

All data was analysed using the statistical program SPSS 22.0 (IBM, Chicago, IL). Demographic characteristics of all participants are presented in Table 1.

\section{Lesions according to the anatomical structure}

Data analysis revealed that there were a total of 110 injuries along 
the full 2013-14 session, including preseason and the competitive period.

Figure 1 shows the global percentages of the injuries recorded:

- Upper limbs, which included: fingers, hand, wrist, forearm, elbow, arm and shoulder, $14 \%$

- Lower Limbs, which included: fingers, foot, ankle, leg, knee, thigh and hip, $65 \%$

Column, which included: cervical, thoracic, lumbar, sacrum and coccyx, $17 \%$

- Head, which included: skull, face, teeth, $4 \%$

We can see that most injuries occurred at the lower limbs, followed by injuries in the colum, in the upper limbs and in the head. There were no injuries to the trunk.

If we take a closer look to the data, Table 2 shows that in the upper limbs, with a total of 16 injuries, the largest number occurred in the fingers: $43.75 \%$, followed by the shoulders: $31.25 \%$, the elbows: $18.75 \%$ and finally the hand: $6.25 \%$. There was no injury to wrists, arms or forearms.

If you look at the data of the lower limbs, with a total of 71 injuries, knee injuries have been the most frequent: $28.18 \%$, followed by the thighs: $23.94 \%$, leg and ankle: $16.90 \%$, feet: $5.64 \%$ and finally fingers and hips matched at $4.22 \%$. In the case of the column, with a total of 19 lesions, the lumbar vertebrae has been the most commonly injured part: $52.64 \%$, followed by the cervical and dorsal areas: $21.05 \%$ each, and, finally, the coxis: $5.26 \%$. In the case of the head, $100 \%$ of the injuries were located in the face.

Table 1: Participants' demographic characteristics.

\begin{tabular}{|c|c|c|}
\hline & Mean & Standard Deviation \\
\hline $\begin{array}{l}\text { Age } \\
\text { (years) }\end{array}$ & 23.45 & 5.44 \\
\hline $\begin{array}{l}\text { Weight } \\
(\mathrm{kg})\end{array}$ & 71.98 & 9.98 \\
\hline $\begin{array}{l}\text { Height } \\
(\mathrm{cm})\end{array}$ & 174.14 & 5.78 \\
\hline $\begin{array}{l}\text { Sum of } 6 \text { skinfolds } \\
(\mathrm{mm})\end{array}$ & 107.73 & 29.24 \\
\hline
\end{tabular}

Injuries according to anatomical structure

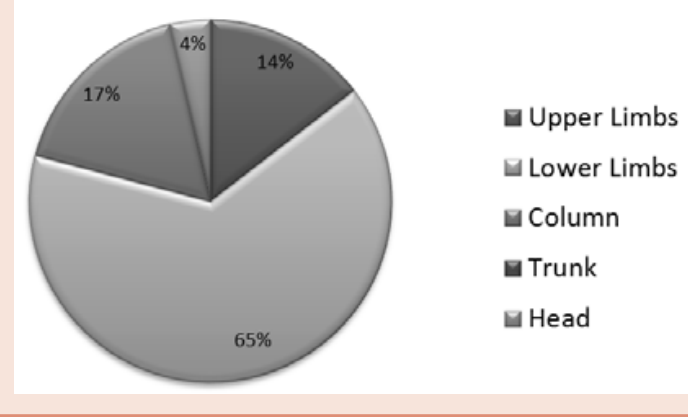

Figure 1: Lesions according to anatomical structure.
Table 2: Lesions according to body part involved.

\begin{tabular}{|l|c|c|}
\hline BODY PART & $\begin{array}{c}\mathbf{N}^{\mathbf{0}} \\
\text { Lesions }\end{array}$ & $\begin{array}{c}\text { Body } \\
\text { Percentage }\end{array}$ \\
\hline UPPER LIMBS & $\mathbf{1 6}$ & $\mathbf{1 4 \%}$ \\
\hline Fingers & 7 & 6.56 \\
\hline Hand & 1 & 0.94 \\
\hline Elbow & 3 & 2.81 \\
\hline Shoulder & $\mathbf{7 1}$ & 4.69 \\
\hline LOWER LIMBS & 3 & $65 \%$ \\
\hline Fingers & 4 & 2.75 \\
\hline Feet & 12 & 3.66 \\
\hline Ankle & 12 & 10.98 \\
\hline Leg & 20 & 10.98 \\
\hline Knee & 17 & 18.32 \\
\hline Thigh & 3 & 15.56 \\
\hline Hip & 19 & 2.75 \\
\hline COLUMN & 4 & $17 \%$ \\
\hline Cervical & 4 & 3.58 \\
\hline Thoracic & 10 & 3.58 \\
\hline Lumbar & 1 & 8.95 \\
\hline Coccyx & 4 & 0.89 \\
\hline HEAD & 4 & 3.58 \\
\hline Face & & \\
\hline
\end{tabular}

The last column shows total body percentages.

\section{Time of the season}

If we take a look at the time of the season of the lesional indicence, the largest number of injuries occurred during the month of October: $22.76 \%$, followed by February: $21.38 \%$ and November: $15.17 \%$. The rest of the months had a similar percentage: $9 \%$.

\section{Period and cause}

We also wanted to know the period (practice or competition) and the cause of the injuries (contact, non-contact, overuse, previous injury, external). Regarding the period, $70 \%$ of the injuries occurred in practice, while only $17 \%$ took place in an official match. The rest of lesions (13\%) were due to external causes.

Regarding the cause of the injury, 35\% were caused by contact, as well as overuse, while $12.5 \%$ were non-contact, being almost irrelevant external causes or previous injuries.

These results show us that there are far more injuries during practice than competition. Previous studies have showed the same trend [8]. Intensity and type of game can cause situations of contact that can trigger a lesion with relative ease.

\section{Recovery time}

Results showed that the majority of the injuries had a recovery period of less than a week: $57 \%$; a smaller percentage took between one and 4 weeks: $31 \%$, and only $12 \%$ required more than a month for a complete recovery.

During the complete basketball season, there were a total of 286 sessions of physical therapy, which yielded an average of 26 sessions for each player. Finally, the mean number of physical therapy session by injury was 2.6 . 
Results also showed that none of the injuries prevented the players from participating in any official match, and the number of workouts lost throughout the season was just 23 (almost insignificant).

\section{Typology and cause}

Figure 2 shows the different injuries recorded based on their typology (muscular, tendinous, contusions). The vast majority were muscular $46 \%$, a very high percentage due to overload and contractures (83\%). The hamstring muscles and the triceps surae were the most affected by the overloads in the lower limbs, followed by the quadriceps. Lower back pains by overload were the most common lesion presented at the level of the back, along with contractures.

$19 \%$ were produced at the joints, and $67 \%$ of them were sprains. The most widespread injury was the ankle sprain, and secondly, the knee sprain.

$18 \%$ of the injuries were contusions, especially in the lower limbs, caused in its greatest extent by bumps during contacts between players. Previous studies have showed that this cause is very common in basketball [4].

A total of $10 \%$ were tendinous injuries. All of them were tendinitis, being the patella and the Achilles the most affected body parts.

Only 6\% were bone injuries, almost all due to vertebral locks.

\section{Recovery techniques}

All of the lesions were treated using with manual techniques. Relieving and relaxing massages were sufficient to solve all the problems with the muscles of the players. Cryotherapy and contrast bath (cold-hot) also helped.

Kinesio-taping was also a widely used technique, because of its comfort and efficiency, apart from the classic functional taping.

The use of osteopathy was also widespread throughout the season. Under the certainty of the interrelationship between all systems of the body, the weaknesses in the musculoskeletal system may affect the rest and vice versa. Hence, the importance of restoring all the functions globally, for quicker recovery and avoid to the extent possible relapses [5].

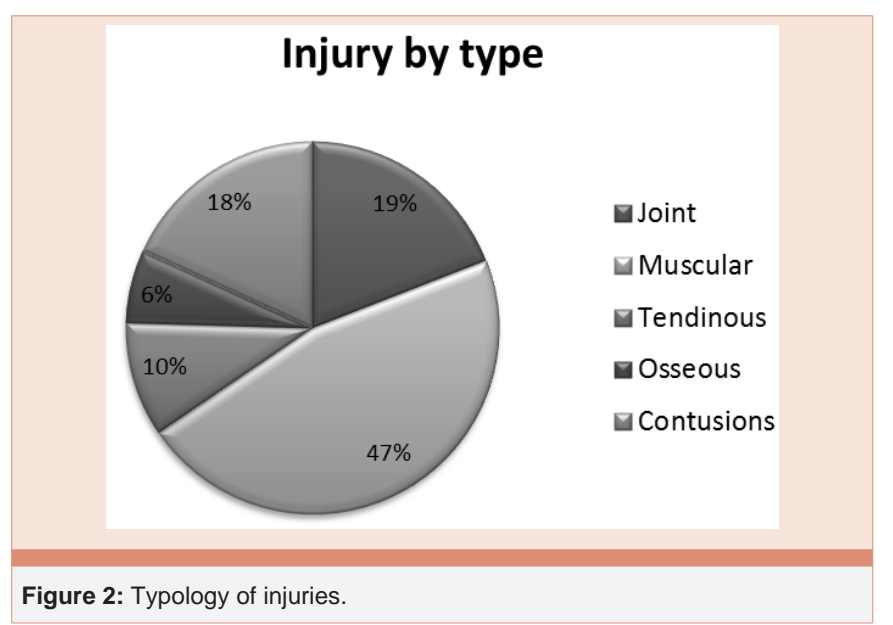

The main aims of therapy are: relieve pain, control inflammation and accelerate repair. Conventional approaches to sports injuries include RICE (rest, ice, compression and elevation), antiinflammatory drugs, immobilisation and physiotherapy. We also introduced acupuncture techniques to reduce the pain and the inflammation in some pathologies [6].

We regularly used "Osamu Ito technique" to relieve pain. This technique is based in the Acupuncture Extraordinary Vessels. The presence of pain, inflammation or hypersensitivity sensation in an area (knee, lumbar and sacral region specific points) indicates the Curious Vessels master points to be used. It is a simple and effective technique for treating pain in a reduced number of sessions and with the use of only 4 needles. That is the reason why it is interesting in the sports field [7].

Sprains were also treated with acupuncture, in addition to the usual techniques, to reduce inflammation as soon as possible and, thereby, recovery times. We used "ashi points" (local painful points) combined with the acupuncture points required, depending on the area of the sprain. For example, in case of ankle sprain (external ligament), we use the following points: UB60 - UB62 - GB40 -ST41 [8].

More techniques were used with good results, but it is not the target of this article to study in depth the recovery methods.

\section{Conclusions}

In view of all the data, we can conclude that the muscle injuries in the lower limbs and in the back were the most common damages.

Contusions, especially in the lower limbs, were also significant. As expected, the most common articular injuries were ankle sprains. At the tendinous level, the patellar tendinitis was the most repeated injury.

It was during the practices when the majority of injuries occurred, being direct contact and overload the main reasons.

Recovery times were fast, due in large part to the low severity of the injuries.

We also want to highlight that the use of alternative treatment techniques such as acupuncture, produced excellent results.

\section{Acknowledgments}

We would like to thank all the members of ADBA basketball team for their committed participation in this research project.

No financial support was used to carry this study.

\section{References}

1. Consejo Superior de Deportes de España (2013). Memoria 2013, Licencias y clubes. Madrid.

2. Manonelles P (1997) "Incidencia de lesiones deportivas en diferentes medios y lesiones específicas por deportes" en II Curso de prevención de lesiones deportivas, Escuela Aragonesa del Deporte, Dirección General de Juventud y Deporte, Diputación General de Aragón, Zaragoza.

3. Federación Española de Baloncesto (2011) Cuestionario Incidencia Lesional de Clubs. Madrid. 
4. Sánchez FY, Gómez A (2012) Hábitos de entrenamiento y lesionesdeportivas en la selecciónmurciana infantile y cadete de baloncesto 2007. Congresolbérico de Baloncesto. Cáceres.

5. Taylor Still A (1902) Philosophy and Mechanical Principles of Osteopathy. London: McKinley.

6. Ping $L$ (2000) The great book of Chinese Medicine. New York: Harmon.
7. Matsumoto K, Birch S (1986) Extraordinary Vessels. Buenos Aires: Ariel.

8. Azmani M (2007) Manual de Acupuntura del Deporte. Barcelona: Heracles

9. Sánchez F, Gómez A (2008) Epidemiología de las lesiones deportivas en baloncesto. Revista Internacional de Medicina y Ciencias de la Actividad Física y del Deporte 8: 270-281. 